\title{
Sociotechnical Evaluation of Alternative and Innovative Shop Floor Control Systems
}

\author{
J. Slomp \\ Faculty of Technology, HAN University of Applied Sciences, Netherlands
}

Copyright $(2017$ by authors, all rights reserved. Authors agree that this article remains permanently open access under the terms of the Creative Commons Attribution License 4.0 International License

\begin{abstract}
In this paper we present a sociotechnical evaluation of three new, and alternative shop floor control systems used in high-variety/low-volume part manufacturing. The three alternative systems concerns the application of (i) POLCA, a card-based system to connect semi-autonomous cells, (ii) LPC (Lean Production Control), a detailed scheduling system to guide the flow of work in a low-volume/high-variety system, and (iii) the CONWIP/FISFOS/TAKT system, a system which limits the amount of work at the workfloor and only indicates priorities on job order level. We show how sociotechnical principles can be used to assess alternative shop floor control concepts. Concurrently, we discuss workplace innovation by means of the alternative shop floor control systems.
\end{abstract}

Keywords Sociotechnical Principles, Shop Floor Control, Workplace Innovation

\section{Introduction}

This paper concerns a sociotechnical assessment of some innovative shop floor control systems used in high-variey/low-volume part manufacturing. Many SME companies can be characterizes as high-variety/low-volume companies. Each job may require a different routing through the manufacturing department. Also lead times of jobs may differ substantially. Furthermore, the number of jobs in the orderpool of a company may vary in the course of time. It is difficult to balance the load on the workfloor such that short and reliable delivery times are realized, in an efficient way. This is the reason why there is so much research in the area of job scheduling and interest in practice for shop floor control systems. A well-controlled manufacturing system supports the control of lead times in manufacturing companies. See figure 1.

Many scheduling algorithms can be found in the scientific literature. It is difficult to find applications in practice. There are many reasons for this practicality gap. Scheduling algorithms presented by scientists are mostly complex, and practitioners prefer inferior solutions above complex algorithms. It may be costly to implement the complex algorithms. Also, much data is needed, which is mostly not available. Furthermore, it is doubtful to what extent the scheduling algorithms come up with good solutions. When proving the optimality of the algorithms, scientists assume that the available data is correct. They also assume that their model of reality (e.g. number of machines, capabilities of machines, working times, etc.) do grasp the most important elements of the real system. This may not be true. Variability in processing times needed by different workers, variability in the number of available workers, and the presence of sequence-based setup times are, amongst other things, issues which are rarely incorporated in scheduling algorithms. Most scheduling algorithms assume single resource problems (only machines), while reality has to cope with multi resource problems (machines, workers, fixtures, etc.).

An important issue is the allocation of the scheduling task. In case of using computer support, the task mostly has to be performed by a planner, on his office. From a Lean perspective, scheduling has to be integrated in the manufacturing system. From a sociotechnical viewpoint, the workers responsible for the manufacturing tasks should also perform the scheduling (i.e. sequencing and dispatching) of jobs. By doing so, they will not be confronted by unrealistic scheduling plans. Although decentralizing the scheduling task to the workfloor may seem attractive, it may be questioned to what extend workers are able to perform the scheduling task satisfactorily. Some support may be needed.

Brown et al. ([1]8, pp.266-267) mention the need to apply socio-technical principles in the design of a production control system. In their opinion, the relative failure of many 'production management systems' (here: shop floor planning and control systems) can be explained, at least partially, in terms of the lack of a true socio-technical approach to the design and installation of these systems (pp.266). They criticize the overemphasis on 
the technical aspects of production control systems and argue that disappointments arise because of failure to give regard to the social aspect system.

In this paper, we argue that sociotechnical principles can be used for selecting an appropriate shop floor planning \& control system. For this purpose, we adopted the sociotechnical principles as formulated by Cherns ([2] and [3]). We will illustrate the applicability of the principles by evaluating three innovative and alternative shop floor planning and control systems, successfully applied in practice. In section 2 , we give a short overview of sociotechnical principles. Section 3 is used to describe the three shop floor planning and control systems 3 . In section 4, we evaluate the three systems by means of the sociotechnical principles. Finally, section 5 discusses the results of our study and gives the main conclusions of our study.

\section{Applying Sociotechnical Principles for the Design of a Shop Floor Control System}

A key term which may cover the meaning of the socio-technical idea is 'self-organization'. Self-organization has to be realized through the design of a production structure as well as the design of a control structure.
Self-organization has to be seen as a means to realize the objectives of an organization and its workers. Each situation requires its own degree of self-organization. The more complex tasks are, and the more variety to deal with, the higher the required level of self-organization. Self-organization refers to the result of the design process as well as to the design process itself (see e.g. Cherns, [2].

A well-known list of socio-technical design principles, which supports the idea of self-organization, is given by Cherns ([2] and [3]). Table 1 gives a brief summary of the principles. Several authors have used the list of Cherns as a starting point for analysis. Huber and Brown [4] use Cherns' list to recover human resource issues in cellular manufacturing. Hyer et al. [5] apply the principles of Cherns in the design of manufacturing cells. Slomp and Ruel [6] illustrate the use of the principles in the design of a planning and control system. Eason [7], Clegg [8] and Doherty [9] elaborated on the work of Cherns. In this paper, we apply the concise list of principles, formulated by Cherns [3] to compare three new and innovative shop floor control systems. This serves the goal of this paper: to show the usefulness of sociotechnical principles in the evaluation of some new and innovative shop floor control systems. Some of Cherns' principles refer to the (re-)design process, other principles concern the characteristics of an ideal design.

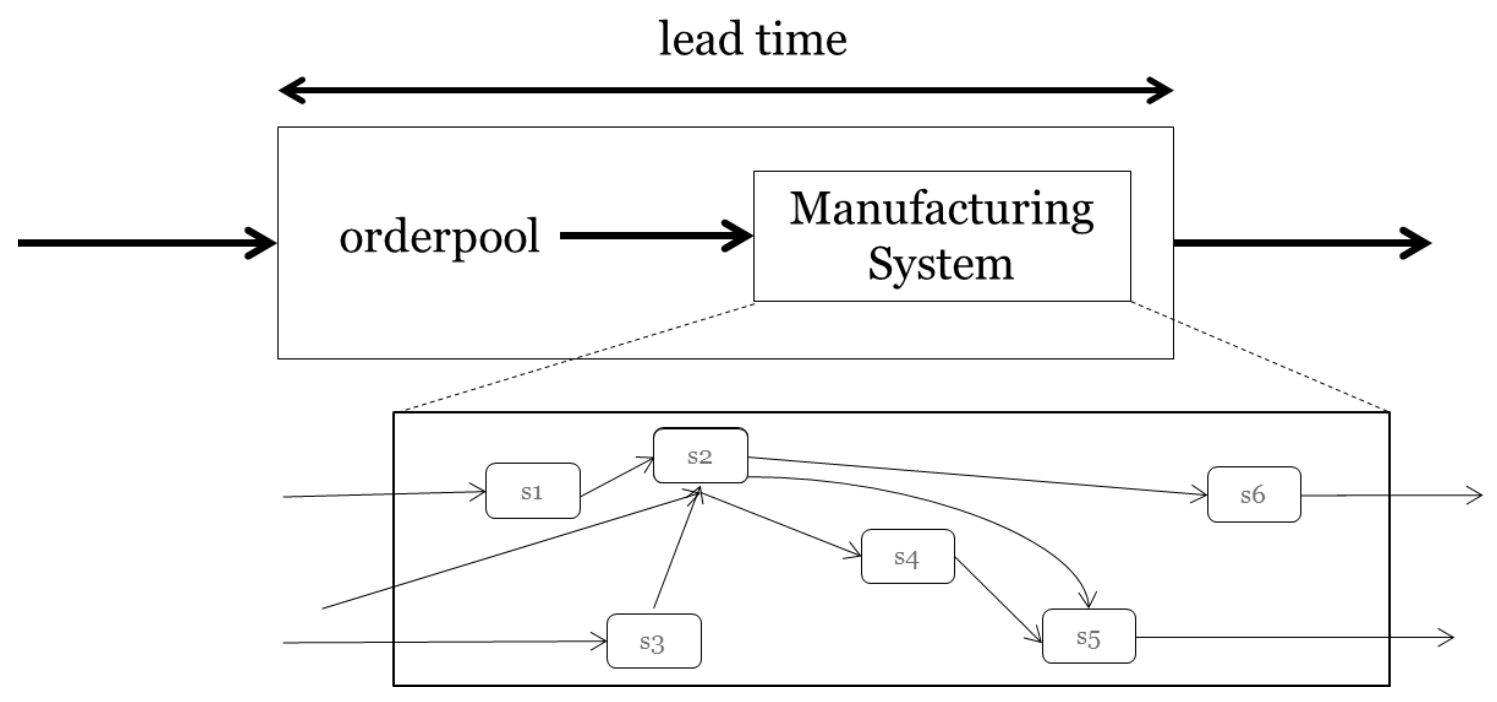

Figure 1. Schematic representation of a 


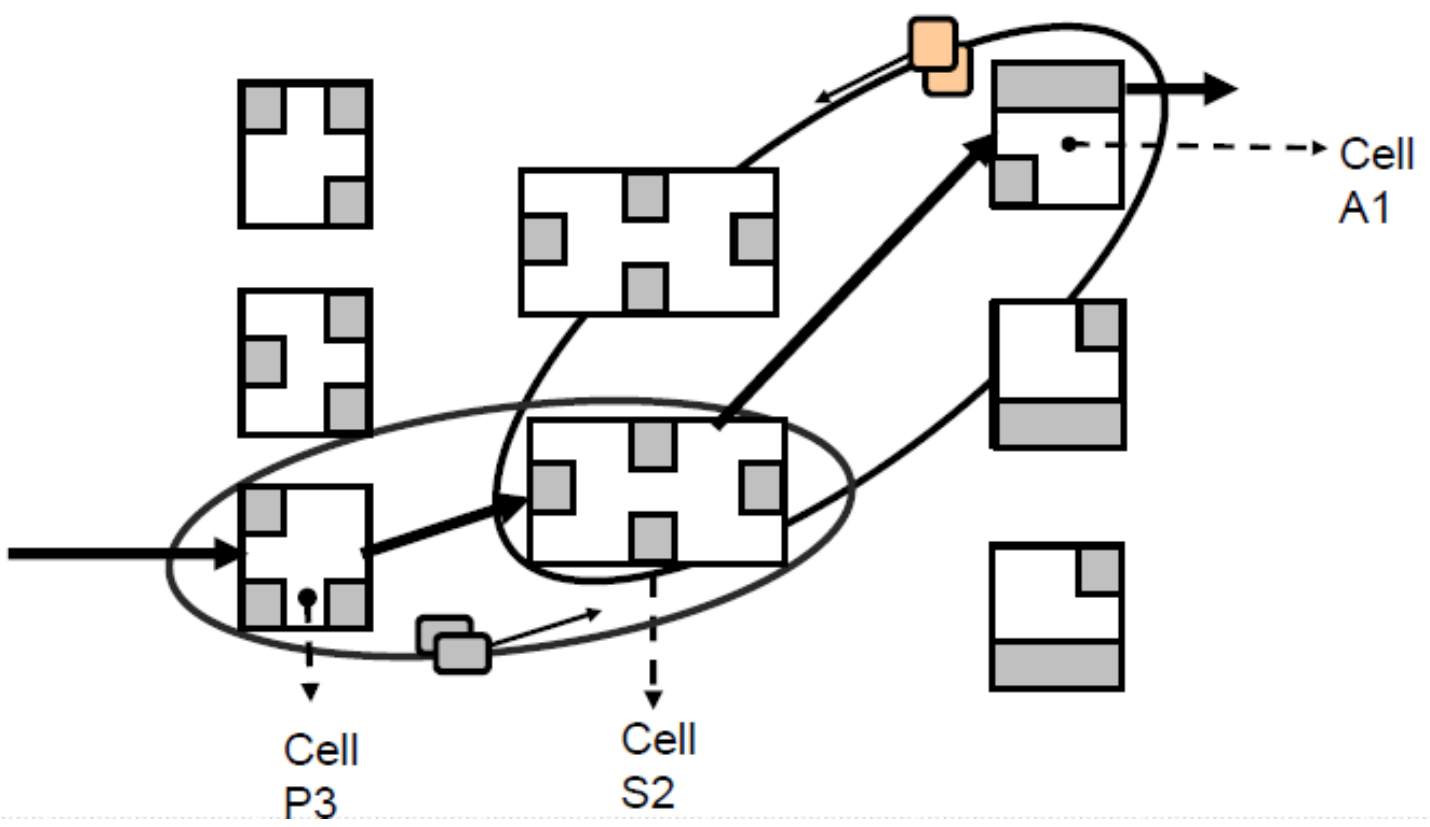

Figure 2. POLCA: a self-balancing system

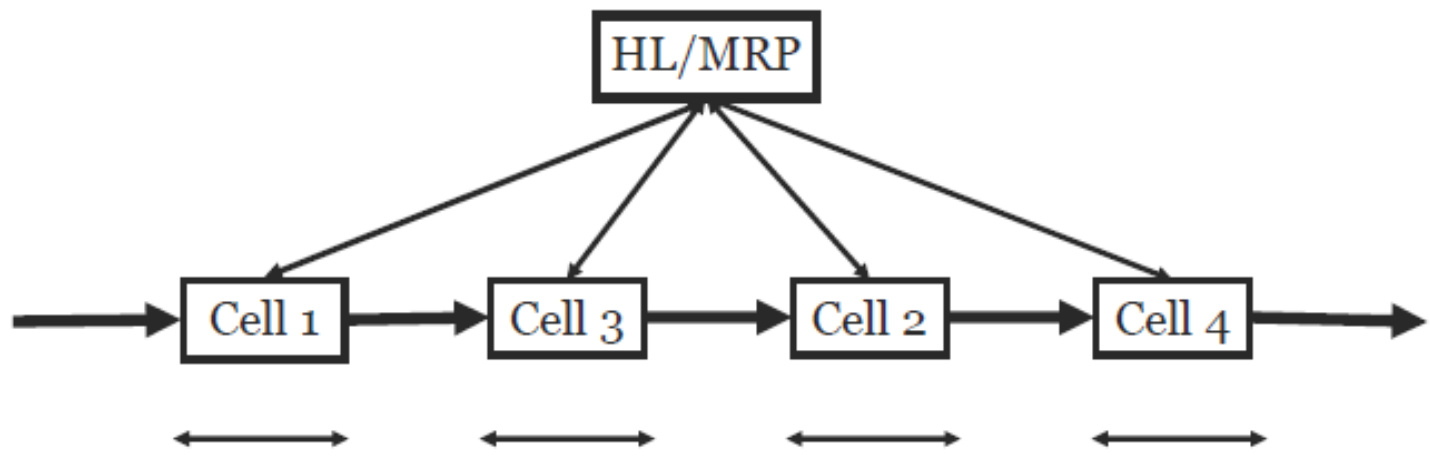

Figure 3. High level MRP to control the loading of the cells

Table 1. Socio-technical design principles (derived from Cherns [3])

\begin{tabular}{|c|c|c|}
\hline Principle & Explanation & Focus \\
\hline 1. Compatibility & The way in which design is done should be compatible with the design's objective. & Design process \\
\hline $\begin{array}{l}\text { 2. Minimal critical } \\
\text { specification }\end{array}$ & $\begin{array}{l}\text { No more should be specified than is absolutely essential. What is essential should be } \\
\text { specified. }\end{array}$ & Design outcome \\
\hline 3. Variance control & $\begin{array}{l}\text { Variances should not be exported across unit, departmental, or other organizational } \\
\text { boundaries. }\end{array}$ & Design outcome \\
\hline 4. Boundary location & $\begin{array}{l}\text { Boundaries should not be drawn so as to impede the sharing of information, } \\
\text { knowledge, and learning. }\end{array}$ & Design outcome \\
\hline 5. Information flow & Information for action should be directed first to those whose task it is to act. & Design outcome \\
\hline 6. Power and authority & $\begin{array}{l}\text { Those who need equipment, materials, or other resources to carry out their } \\
\text { responsibilities should have access to them and authority to command them. }\end{array}$ & Design outcome \\
\hline $\begin{array}{l}\text { 7. The multi-functional } \\
\text { principle }\end{array}$ & $\begin{array}{l}\text { If the environmental demands vary, it then becomes more adaptive and less wasteful } \\
\text { for each element to possess more than one function. }\end{array}$ & Design outcome \\
\hline 8. Support congruence & $\begin{array}{l}\text { Systems of social support (systems of selection, training, conflict resolution, work } \\
\text { measurement, etc.) should be designed so as to reinforce the behaviors which the } \\
\text { organization structure is designed to elicit. }\end{array}$ & Design outcome \\
\hline 9. Transitional organization & The design team and its process should be seen as a vehicle of transition. & Design process \\
\hline 10. Incompletion & $\begin{array}{l}\text { Design is a reiterative process. The closure of options opens new ones. At the end we } \\
\text { are back at the beginning. }\end{array}$ & Design process \\
\hline
\end{tabular}


The principles concerning the process can be used in the design process of a shop floor control system (SFCS). An SFCS is a system which asks for cooperation of the workers. They have to accept the rules of the system. Most important is that the workers feel that the system is helpful for them to select the next job to work on and, subsequently, to realize their targets with respect to efficiency and delivery performance. They need to cooperate with the system. The compatibility principle (principle 1) demands that the process and the outcome of a design should be compatible. Therefore, workers should be able to participate in the design, or at least in the selection, of the SFCS. The principle of Transitional Organization (principle 9) demands that the main designer/selector of the SFCS should also be responsible for the implementation of the system. The principle of Incompletion (principle no. 10) recognizes the fact that shop floor control will need development in the course of time, because of a changing context and/or improvement ideas. There should be room for improvement. It is not easy to change a fully automated system...

The principles concerning the outcome of the design process give some guidelines for designing a successful SFCS. The principle of Minimal Critical Specification (principle 2) demands a careful specification of the essential elements of shop floor control support needed by the workers. Only these elements should be dealt with by the SFCS. The SFCS should not unnecessarily limit the freedom of the worker to take planning and control decisions. The principle of Variance Control (principle 3) Cherns states that variances should not be exported across unit, departmental, or other organizational boundaries. This means that each organizational level in a production control system should be able to cope with the variances that may arise at that level. In other words, decision making tasks (levels) should reflect the variances that may arise at the organizational level. A machine breakdown, for instance, should ideally not ask for actions of the planning department. The workfloor should be able to cope with these disturbances. The principle of Boundary Control (principle 4) says that boundaries should not be drawn so as to impede the sharing of information, knowledge, and learning. The principle contributes to the considerations with respect to the assignment of decision tasks and responsibilities to the organizational levels. Principally, all levels should contribute to the overall objectives of the production control system. Because of the complexity of the planning and scheduling functions, however, each of the levels of the decision and organization hierarchy may have its own objectives. It is required that these objectives are tuned to one another. A system of co-ordination (= sharing of information, knowledge, and learning) is needed to avoid sub-optimizations. The principle of Information Flow (principle 5) says that the required design of the information system, which is part of the SFCS, depends on the division of tasks and responsibilities. If workers are responsible for efficiency and delivery performance then they should be informed first if they should act. The principle of Power and Authority (principle 6) stresses the importance that workers, who have to act, should have access to the means of the SFCS. This may be difficult in case a computer is needed to determine which action have to be taken. The Multifunctional Principle (principle 7) creates awareness for the fact that decision support tools, which can only be used by one employee, for instance the foreman of a work group, are not usable if the employee is absent. The principle of Support Congruence (principle 8) is related to the context of the SFCS. If workers become responsible for the planning, scheduling and control of their tasks, then it is likely that they become also responsible for other decision making tasks (e.g. hiring temporary personal, organizing preventive maintenance, etc.). The support systems in a company should be congruent.

\section{Three Innovative, Alternative Shop Floor Control Systems for High-Variety/Low-Volume Environments}

This section describes shortly three innovative, and alternative, Shop Floor Control Systems. These systems will be assessed in section 4 by means of the sociotechnical principles. The three alternative systems are:

- POLCA, a card-based system to connect semi-autonomous cells;

- $\quad$ LPC (Lean Production Control), a detailed scheduling system to guide the flow of work in a low-volume/high-variety system;

- The CONWIP/FISFOS/TAKT system, a system which limits the amount of work at the workfloor and only indicates priorities on job order level.

POLCA and CONWIP/FISFOS/TAKT both recognize the importance of limiting the number of jobs in the system. This is an important element in the control of throughput times of jobs. The systems embrace the concept of pull. See Spearman et. al [10]. The LPC is a scheduling system which is focused on realizing short throughput times while simultaneously considering machine bottlenecks. Basically, the system solves the shifting bottleneck problem, without the complex algorithms presented in literature, see e.g. Adams et.al [11]. The LPC is basically a push system.

\subsection{POLCA}

POLCA stands for Paired-cell Overlapping Loops of Cards Authorization and is developed by Suri [12] as part of the Quick Response Manufacturing (QRM) toolbox. In POLCA the manufacturing department is divided in a limited number of cells, each responsible for a number of operations. The division is done in such a way that the number of flows between cells is limited. If a flow exists 
between two cells, than a loop between these cells is created and a limited number of cards is in this loop. A worker is only allowed to perform an operation on a job if two cards are available: a card also belonging to the cell where the job is coming from and a card also belonging to the cell where the job has to go to next, see figure 2. Furthermore, the operation has to be performed after an earliest starting date and before a latest finishing data determined by a high level MRP system, see figure 3.

Basically, POLCA is a self-balancing system. MRP takes care that cells are not overloaded in the course of time. The card system directs jobs to cells where capacity (i.e. free cards) is available. Furthermore, the total number of cards in the system limits the number of jobs in the whole system. This takes care of short lead times.

POLCA is used in several companies, in USA as well as Europe. One of the companies where POLCA is used, is Variass B.V. (Veendam, The Netherlands). Management is very satisfied with the system. A central board is used for all available cards (i.e. cards not connected to jobs), see figure 4 . The central board makes clear to all workers which cell needs new jobs (many cards) and which cell has probably to less capacity (no or few cards). The information on the board helps to make sequencing and dispatching decisions in the cells. Furthermore, it provides information for the manager of the department to allocate workers to another cell, if needed.

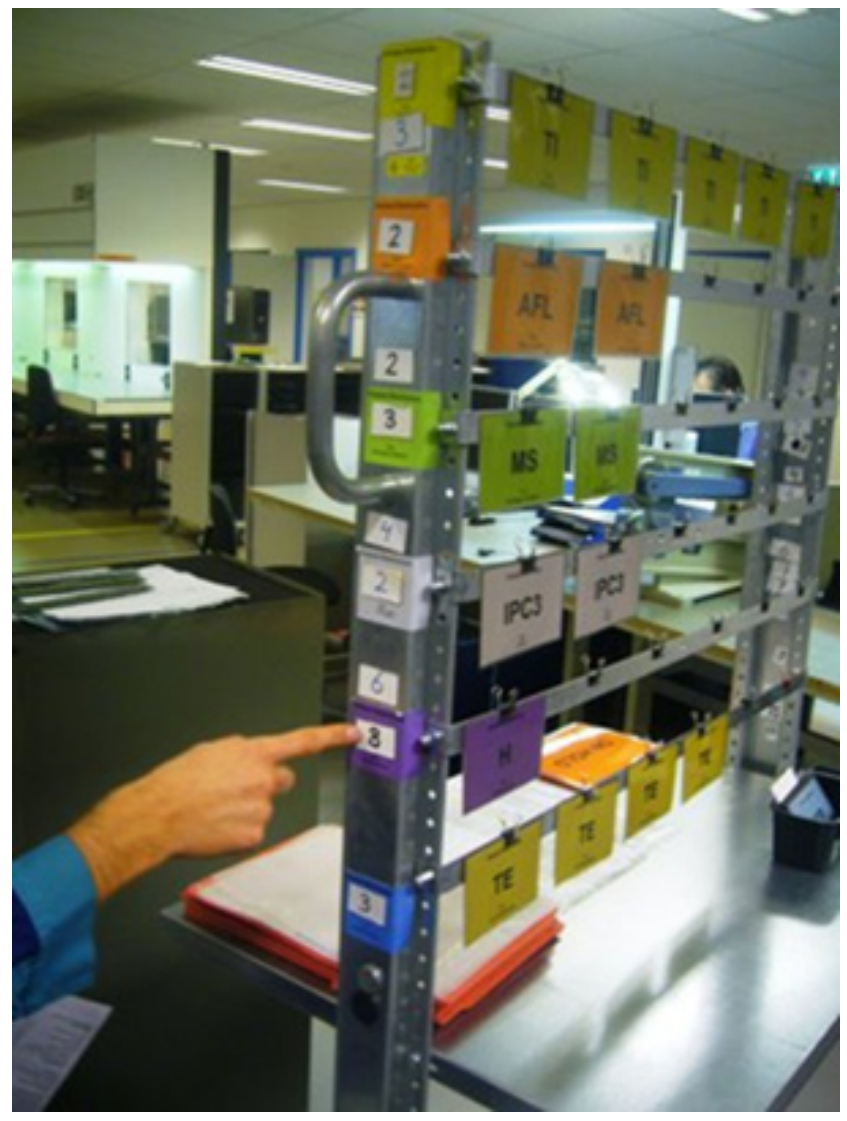

Figure 4. POLCA cards indicating the need for jobs. The manager points to the number of workers in a cell (photo made by the author of the paper)

\subsection{Lean Production Control (LPC)}

The Lean Production Control (LPC) system is developed by Raukema Bedrijfsprocessen, see: http://www.raukema.nl/. The system is used in several companies in the Netherlands. Also companies in other countries are interested in the system. Basically, the LPC system creates a Gantt Chart, showing the sequence and timing of manufacturing orders, see figure 5. The Gantt Chart is usually made daily by a department planner. Input comes from the MRP system of the company. There is mechanism in the software to support the scheduler. Main mechanism is that all operations of a job are scheduled sequentially, starting with the operation which needs the bottleneck machine.

One of the companies using the LPC system is Neopost Drachten (The Netherlands). They have several digital screens on the workfloor, showing the Gantt Chart. When finishing an operation, the worker has to inform the system by means of scanning the barcode of the operation of the order. Immediately, the changing status of the operation is visible on the screens. The screens show which operations are in time, and which are too late. This informs the workers what to do next. It is the challenge for the operators to perform all operations in time. The scheduling does not change during day time.
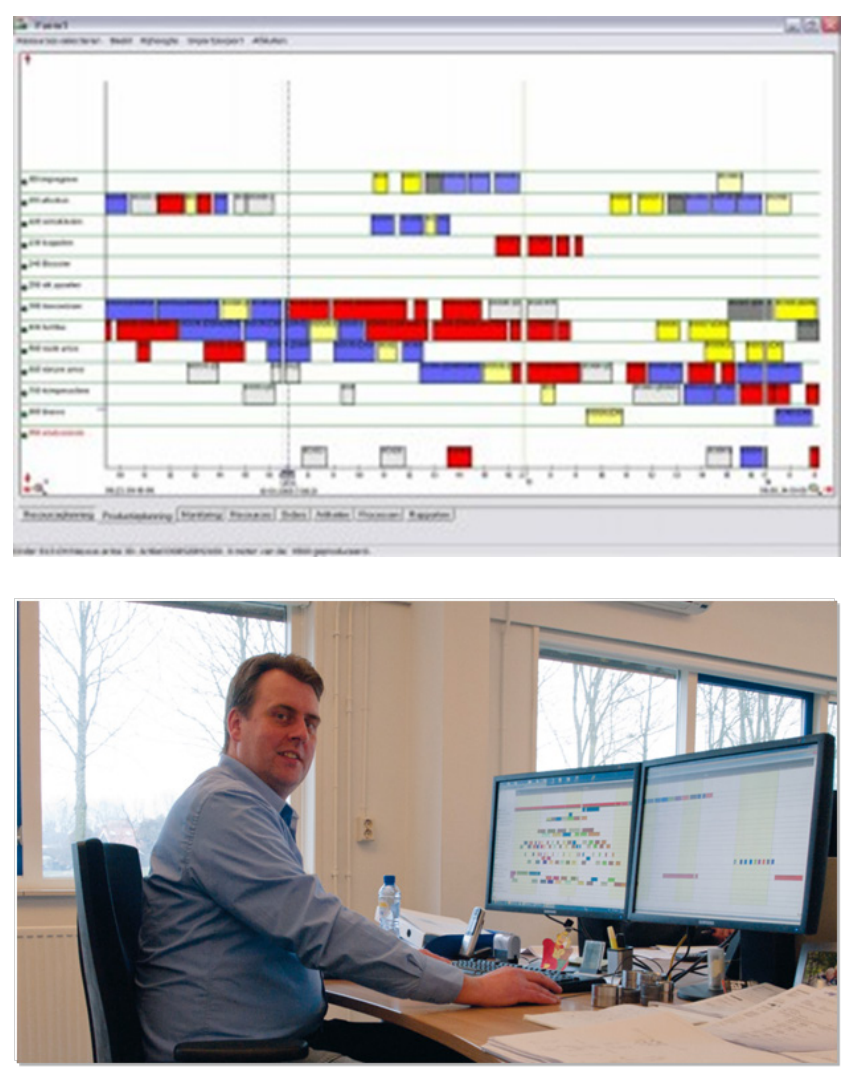

Figure 5. The Lean Production Control system.

\subsection{The CONWIP/FISFOS/TAKT System}

The CONWIP/FISFOS/TAKT system is developed at 
Eaton Holec (Hengelo, The Netherlands) and is described in two papers (Slomp et al. [13] and Bokhorst and Slomp [14]). The system is first developed for the cupper department of the company. Later, it is also implemented in other departments. The system is now used in several companies.

In the system, the number of jobs is limited to a certain number (CONWIP). This takes care of a short average throughput time of jobs. Next, workers are stimulated to work on the jobs that are longest in the system (First In System, First Out System, FISFOS). This takes care of, more or less, equal throughput times of jobs. Finally, workers get information about the real and desired number of orders to be produced at each time.
An important element in the CONWIP/FISFOS/TAKT system is the so-called Production Progress Screen, see Figure 6. This screen shows the number of jobs in the system (18 jobs in Figure 6), the jobs which needs most attention (job 688390 is already too late), and the difference between the real number and the planned number of orders to be produced at each moment (11 orders ahead). The screen was initially programmed in Excel. Later the screen was reprogrammed and integrated in the ERP system of the company. The Production Progress Screen is positioned somewhere in the department, visible for all workers, see figure 7.

\begin{tabular}{|c|c|c|c|c|c|}
\hline \multicolumn{6}{|c|}{ Production progress screen } \\
\hline Day & Wed & Start & 06:00 am & Finished products & 26 \\
\hline Takt time (min) & 18 & Stop & $11: 00 \mathrm{pm}$ & To be produced & 34 \\
\hline Daily production & 60 & Time & $10: 33 \mathrm{am}$ & Lead/backlog & 11 \\
\hline
\end{tabular}

\begin{tabular}{|lll||lll||lll||lll||}
\hline Nr. & Order & Time & Nr. & Order & Time & Nr. Order & Time & Nr. & Order & Time \\
\hline 41 & 688390 & $23: 34$ & 54 & 687872 & $03: 50$ & 19 & 0 & $00: 00$ & 38 & 0 & $00: 00$ \\
17 & 688140 & $16: 36$ & 16 & 688238 & $02: 58$ & 20 & 0 & $00: 00$ & 40 & 0 & $00: 00$ \\
47 & 688131 & $15: 47$ & 3 & 688202 & $01: 34$ & 21 & 0 & $00: 00$ & 43 & 0 & $00: 00$ \\
11 & 688184 & $13: 17$ & 1 & 0 & $00: 00$ & 22 & 0 & $00: 00$ & 45 & 0 & $00: 00$ \\
44 & 688221 & $11: 50$ & 2 & 0 & $00: 00$ & 23 & 0 & $00: 00$ & 48 & 0 & $00: 00$ \\
46 & 688239 & $10: 46$ & 4 & 0 & $00: 00$ & 24 & 0 & $00: 00$ & 49 & 0 & $00: 00$ \\
29 & 687899 & $10: 38$ & 5 & 0 & $00: 00$ & 25 & 0 & $00: 00$ & 51 & 0 & $00: 00$ \\
10 & 687873 & $10: 34$ & 7 & 0 & $00: 00$ & 28 & 0 & $00: 00$ & 52 & 0 & $00: 00$ \\
39 & 688237 & $08: 54$ & 8 & 0 & $00: 00$ & 30 & 0 & $00: 00$ & 53 & 0 & $00: 00$ \\
34 & 687874 & $08: 39$ & 9 & 0 & $00: 00$ & 31 & 0 & $00: 00$ & 55 & 0 & $00: 00$ \\
50 & 687900 & $08: 33$ & 12 & 0 & $00: 00$ & 32 & 0 & $00: 00$ & 56 & 0 & $00: 00$ \\
6 & 688405 & $06: 34$ & 13 & 0 & $00: 00$ & 33 & 0 & $00: 00$ & 57 & 0 & $00: 00$ \\
26 & 688402 & $06: 03$ & 14 & 0 & $00: 00$ & 35 & 0 & $00: 00$ & 58 & 0 & $00: 00$ \\
27 & 688395 & $04: 26$ & 15 & 0 & $00: 00$ & 36 & 0 & $00: 00$ & 59 & 0 & $00: 00$ \\
42 & 688387 & $04: 10$ & 18 & 0 & $00: 00$ & 37 & 0 & $00: 00$ & 60 & 0 & $00: 00$ \\
\hline
\end{tabular}

Figure 6. The production Progress Screen (part of the CONWIP, FISFOS, TAKT system). 


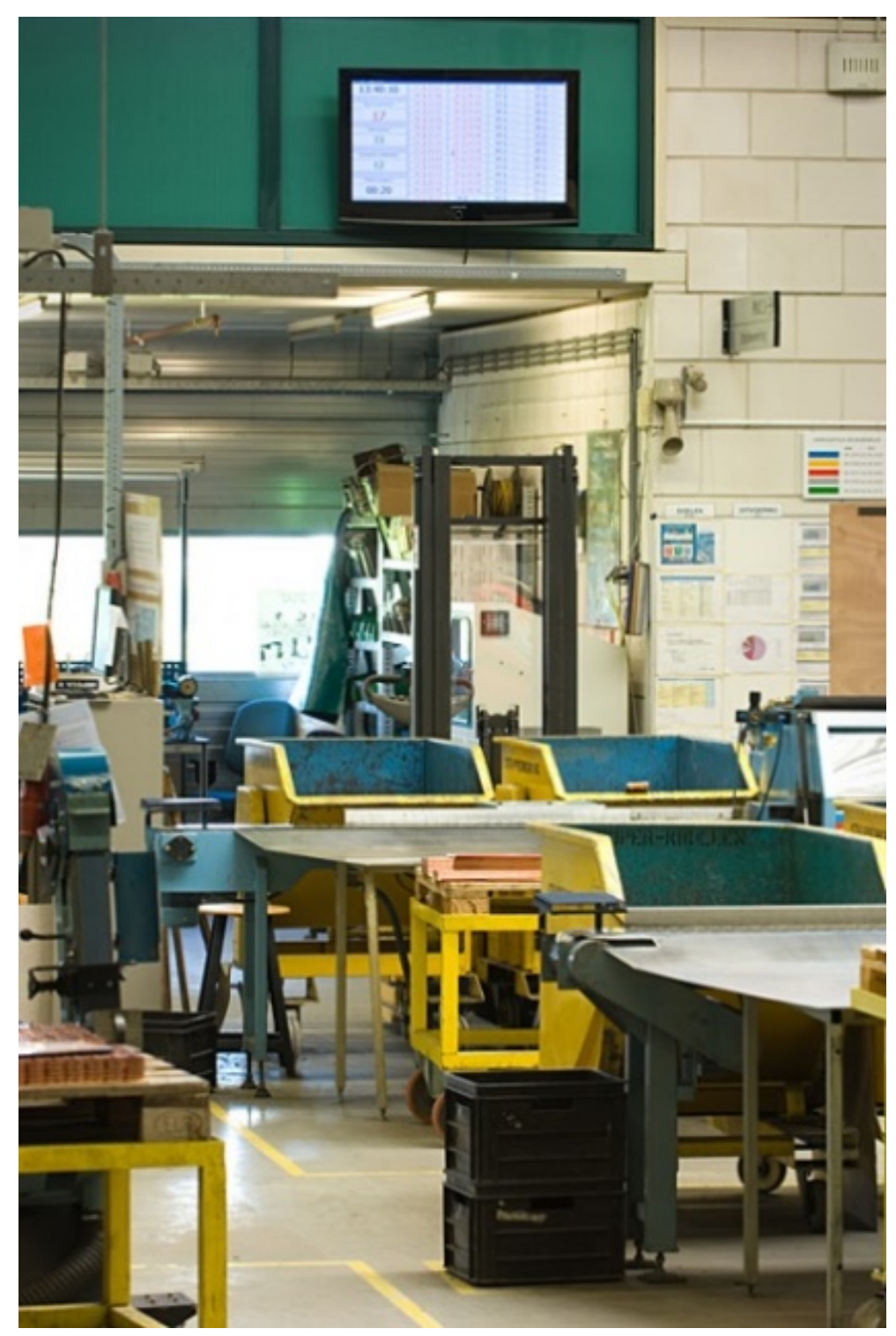

Figure 7. The production progress screen, connected to the wall.

Table 2. Assessment of the three SFCS by means of sociotechnical design criteria.

\begin{tabular}{|l|l|l|l|}
\hline & \multicolumn{1}{|c|}{ POLCA } & \multicolumn{1}{|c|}{ LPC } & $\begin{array}{l}\text { CONWIP/ } \\
\text { FISFOS/TAKT }\end{array}$ \\
\hline 1. Minimal critical specification & ++ & + (too much? & $\begin{array}{l}+ \text { (too less or } \\
\text { too much) }\end{array}$ \\
\hline 2. Variance control & ++ & + (only local) & + (only global) \\
\hline 3. Boundary location & $\begin{array}{l}++ \text { (previous } \\
\text { and next cell) }\end{array}$ & + (not clear) & ++ \\
\hline 4. Information flow & ++ & + (too much) & o (limited) \\
\hline 5. Power and authority & ++ & 0 & + \\
\hline 6. The multi-functional principle & ++ & $\mathrm{o}$ & $\mathrm{o}$ \\
\hline 7. Support congruence & + time focus & $\mathrm{o}$ & $\mathrm{o}$ \\
\hline
\end{tabular}


Workers at the cupper department of Eaton company have the responsibility to realize their daily target (60 jobs) and to limit the throughput times of jobs, by means of CONWIP and FISFOS. The production progress screen gives sufficient information. They also have to enter the correct jobs to the production progress screen. The planning department of the company daily releases jobs to the cupper department to a level of 2.5 days of work. Each day has its own color. Information sheets of jobs get covers in the color of the day of release. The workers of the cupper department are responsible to finish released jobs within three days. When the first operation of a job starts, then the job enters the production progress screen and one day is available to finish that job. The release level of 2.5 days is used to give the workers of the cupper department the opportunity to cluster jobs for saving setup time. The presence of undesired colored covers at the workfloor and red jobs on the production progress screen is a reason for the production manager of the department to ask what is wrong.

\section{Evaluating the Three Production Control Systems}

All companies are happy with their production control system. The systems serve their needs. The three SFC systems are slightly different and may be the best option in certain cases. If there are shifting bottlenecks (machines), then the LPS may be best. In case of long routings, POLCA may be preferred. Then the department can be divided in cells. In case of a high variety of routings, the CONWIP/FISFOS/TAKT system may be best. For many companies however, the three systems are alternatives. If no other systems are available, then these companies have to make a choice.

With respect to the process of integrating a SFCS in the company, POLCA and CONWIP/FISFOS/TAKT do have substantial advantages. These are simple systems. Development of a POLCA game/simulation is not complex. It is easy to let workers, team leaders, and planners participate (principle 1) in the development of the system. This participation is also highly desirable. The design of a POLCA system (incl. cells) needs to be done customer specific and requires detailed knowledge of the production system. This further supports the Transitional Organization principle (principle 9). POLCA also gives clear improvement parameters: cell lead times and the number of POLCA cards (principle 10). The CONWIP/FISFOS/TAKT system is also simple and can be easily understood by workers. Workers may participate in the setting of the parameters in the system (i.e. CONWIP level, release level). Introduction of the system was easy at Eaton Holec. The operators did not need any training. Parameters for improvement are the number of jobs in the system (CONWIP level) and the output (e.g. jobs per day). This can be measured easily. The LPC system is less easy to implement in a company. Participation of workers in specifying the system for the company is difficult. This also may complicate the acceptance of the system in the company. Improvement parameters are also not that clear for workers at the shopfloor.

Table 2 gives an assessment of the design of the three SFCSs by means of sociotechnical criteria. The assessments will be motivated in the remainder of this section.

POLCA can most easily be adapted to a specific situation. The number of cells and the cell lead times are parameters which can be set, dependent on the particular situation. Cell design also determines the number of loops. In the case described in section 3 , the routings were simple and the POLCA cards were linked to cells instead of loops. The cards were used to identify the 'work-in-next-queue'. The focus of shop floor control was to produce according the dispatching rule 'lowest-work-in-next-queue'. This example shows that POLCA can easily be adapted to a particular situation. The manager of the company did have experience with CONWIP. He enjoyed POLCA because it serves the setting of local and global accountability. CONWIP/FISFOS/TAKT sees a department as a whole and does not offer tools for further specification to the level of machine groups. The LPC asks to specify everything, perhaps too much. Therefore, POLCA seems to be most able to design the SFCS according the principle of minimal critical specification.

POLCA also performs well with respect to the sociotechnical principles of variance control and boundary location. POLCA defines clear decision making tasks connected with the organizational levels. Unit Level Control, or cell control, is guided by the availability of cards and earliest starting and latest finishing dates (which comes from high Level MPR-control). The coordination between cells is taken over by the Paired Overlapping Loops of Cards. High level MRP control takes care of loading the production cells. The divisions of responsibilities are clear. POLCA does not give guidelines for establishing an escalation model: what to do if a cell does not have enough jobs to work on? What to do with SFC if a machine breaks down? When to act? The CONWIP/FISFOS/TAKT and the LPC system are also not clear about coping with unexpected variances. The CONWIP/FISFOS/TAKT system, as implemented at Eaton, illustrates the possibility to clearly divide responsibilities between different levels of the organization. The LPC system is less clear about the division of responsibilities. To what extent may workers deviate from the schedule, which is just based on a model of reality....

POLCA keeps all information gathering and processing on the workfloor. The other two systems also ask for information gathering at the workfloor. However, in case of CONWIP/FISFOS/TAKT only limited information is available. The status of the job is not known when the job is in the system. The LPC system registers everything. Probably too much. It is also questionable who has to take 
action based on the status of the system: the planner, the production manager, or the workers.

With respect to the principle of power and authority, the workers are the owners of the POLCA system. In the case of section 3, the workers developed the system themselves by playing a lego game which corresponded to the situation of the company. They own the system. There is less ownership in case of CONWIP/FISFOS/TAKT and the LPC system. The workers are not able to interact with the systems.

POLCA is also a simple visual system, which don't need software. This simplifies the adherence to the multifunctionality rule. The system is not dependent on specialists. This is different in the other cases, especially in the case of the LPC system.

It is difficult to say much about the principle of support congruence. In the case of POLCA, the system fits in the QRM philosophy of the company. In the case of CONWIP/FISFOS/TAKT, it was difficult to connect the system to the MRP information system. It was/is hard to connect the pull principle of CONWIP/FISFOS/TAKT with the push principle of MRP. The lead time reservation in MRP was not connected to what happened on the workfloor. This also was the case in the LPC example in section 3.

\section{Discussion and Conclusions}

This paper analyses the adherence of three alternative and innovative shop floor control systems to sociotechnical principles. As may be noted, POLCA 'scores' relatively well with respect to sociotechnical principles. This is the result of our analysis. The number of POLCA implementations, however, is limited. One of the reasons may be that the system demands full adherence of the workers to the card system. It may not be easy to gain that steady discipline of all workers. Another reason may be that POLCA demands changes in the MRP system with respect to lead time reservation: each cell (and not operation) has its own lead time. Production managers don't like to change the content of their MRP system. Furthermore, POLCA demands a redesign of the shop floor into a limited number of multi-functional POLCA cells. This may also be an obstacle. It is interesting to further investigate the constraints of POLCA.

The three new and innovative shop floor control systems discussed in this paper, illustrate three ways of thinking about shop floor control: (i)creating connections between semi-autonomous cells (POLCA), (ii) setting clear constraints on which operators can act (CONWIP/FISFOS/TAKT), and (iii) precise scheduling of actions to be performed (LPC). It is likely that certain manufacturing characteristics are best served by a particular way of thinking about shop floor control. The scheduling approach of LPS, for instance, serves the complex situation of shifting bottlenecks. It is interesting to further investigate the link between manufacturing characteristics and the three ways of thinking.

Although certain manufacturing situations may be best served by a particular way of thinking about shop floor control, there is likely a substantial overlap between application areas. In these cases, the managers' preferences play an important role in the selection of a particular system, i.e. way of thinking. This is also an interesting area for research: what determines the preferences of managers?

This paper analyses and compares three innovative shop floor control systems used in high-variety/low-volume part manufacturing in a qualitative way. It is difficult to perform a more quantitative comparison between the different systems and to assess the effect of the systems on throughput times of jobs and delivery performance. This requires a similar situation in which the three systems are used by the same workers. It is not realistic to find such a situation in reality. Experimental, simulation studies may be helpful. A fair comparison between alternative shop floor control systems asks for a more complete study.

This paper illustrates how sociotechnical principles can be used to evaluate alternative shop floor control systems. The analysis in the paper is done in a qualitative way by giving a motivated judgement about the extent in which three innovative shop floor control systems serve the various sociotechnical principles. The way in which the analysis is done, may help managers to articulate sociotechnical concerns in the selection, introduction and specification of a new shop floor control system. Furthermore, understanding the importance of sociotechnical principles may help developers of shop floor control systems to integrate a sociotechnical perspective when designing a new system.

\section{REFERENCES}

[1] Brown, J., Harhen, J., and Shivnan, J (1988), Production Management Systems - A CIM Perspective, Addison-Wesley Publishing Company.

[2] Cherns, A. (1976), The Principles of Socio-technical Design, Human Relations 29 (8), pp. 783-792.

[3] Cherns, A. (1987), Principles of Socio-technical Design Revisited, Human Relations 40 (3), pp. 153-162.

[4] Huber, V., Brown, K. (1991), Human Resource Issues in Cellular Manufacturing. Journal of Operations Management, Vol.10, No.1, pp. 138-159.

[5] Hyer, N.L., Brown, K.A., and Zimmerman, S. (1999), A Socio-technical Systems Approach to Cell Design: Case Study and Analysis, Journal of Operations Management, Vol.17, pp. 179-203.

[6] Slomp, J. and Ruel, G.C. (2001), A Socio-Technical Approach for the Design of a Production Control System: Towards Controllable Production Units, Chapter 18 in: 
Human Performance in Planning and Scheduling: Fieldwork Studies, Edited by B.L. MacCarthy and J.R. Wilson, Taylor \& Francis, London and New York, pp. 383-409.

[7] Eason, K. D. (1988), Information Technology and Organisational Change, London, Taylor \& Francis

[8] Clegg, C. W. (2000), Socio-Technical Principles for System Design, Applied Ergonomics 31, pp. 463-477.

[9] Doherty, N. F. (2014), The Role of Socio-Technical Principles in Leveraging Meaningful Benefits from IT investments, Applied Ergonomics 45, pp. 181-187.

[10] Spearman, M. L., D. L. Woodruff, W. J. Hopp (1990), CONWIP: A pull alternative to kanban. Internat. J. Production Res. 28(5), 879-894.
[11] Adams, J., Balas, E. and Zawack, D. (1988), The Shifting Bottleneck Procedure for Job Shop Scheduling. Management Science, 34, 391-401

[12] Suri, R. (2010), It's about Time, Productive Press.

[13] Slomp, J., Bokhorst, J. A.C. and R. Germs (2009), A lean production control system for high-variety/low-volume environments: a case study implementation, Production Planning \& Control, Vol.20, No. 7, 586 - 595

[14] Bokhorst, J.A.C, and J. Slomp (2010), Lean Production Control at a High-Variety/Low-Volume Part Manufacturer, Interfaces, Vol. 40, No. 4, July-August 2010, pp. 303-312. 